\title{
Neu bei conrad: Konsensustreffen Mammadiagnostik 2021
}

Die aufgezeichneten Vorträge der Reihe „KuKMa - Konsensustreffen Mammadiagnostik 2021“ stehen ab sofort allen Mitgliedern in der DRG-Lernplattform conrad kostenfrei bis zum 31.03.2023 zur Verfügung.

Die spannende, traditionsreiche und für das Fachgebiet der Mammadiagnostik maßgebliche Veranstaltung „Konsensustreffen Mammadiagnostik“ fand im Jahr 2021 komplett online in Form von 3 SchwerpunktWebinaren unter dem Dach von „Akademie Online“ statt. Mit Pro- und Kontra-Vorträgen beleuchtet und anschließend diskutiert wurden die Fragen: Soll die 3D-Tomosynthese mit 2D-Rekonstruktion die Standard2D-Mammografie bereits heute ersetzen? Soll die Mamma-MRT bei dichter Brust immer oder nur im Einzelfall eingesetzt werden? Und: Soll die Mammasonografie bei dichter Brust immer oder nur im Einzelfall eingesetzt werden?
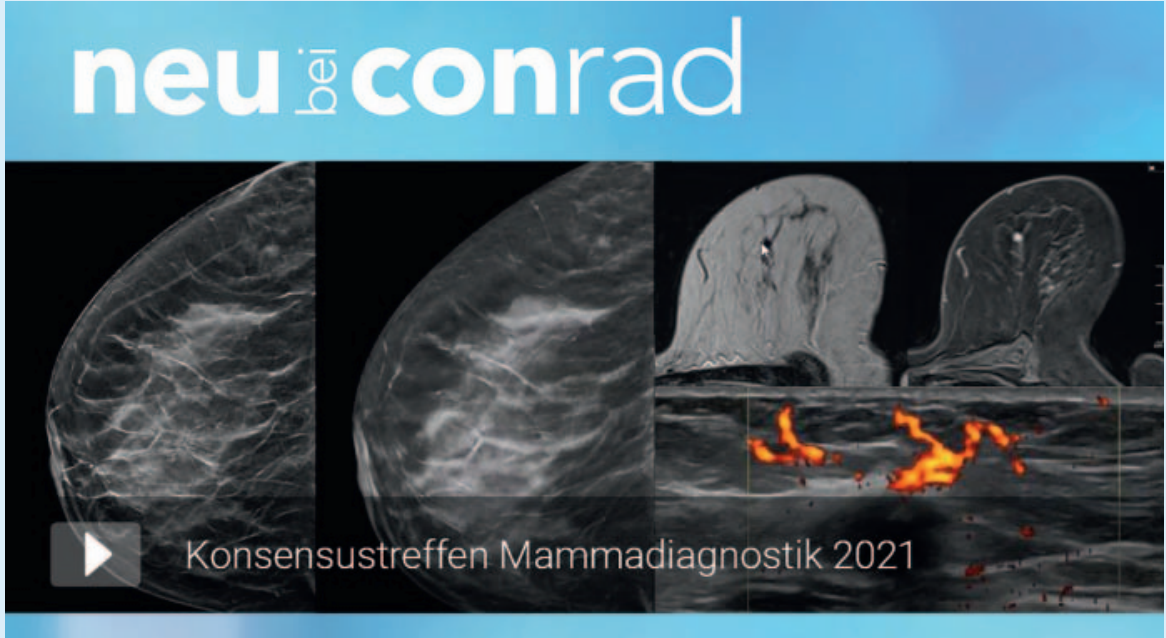

Wissenschaftliche Leitung: M. MüllerSchimpfle

Referentinnen und Referenten: M. Müller Schimpfle, S. Weigel, M. Bernathova, R. Schulz-Wendtland, T. Helbich, K. Sieg-
mann-Luz, P. Baltzer, S. Heywang-Köbrunner, C. Solbach, M. Fuchsjäger, A. Mundinger, W. Bader, M. Golatta

www.conrad.drg.de 